\title{
Assessment of diagnostic accuracy of lung function indices and FeNO for a positive methacholine challenge
}

\author{
N. Bougard*, H. Nekoee, F. Schleich, F. Guissard, V. Paulus, AF Donneau, R. Louis \\ Pneumology and Public Health Department, University of Liege, CHU Liege, Belgium
}

\section{A R T I C L E I N F O}

\section{Keywords:}

Asthma

Methacholine challenge

FEV1

RV/TLC ratio

FeNO

\begin{abstract}
A B S T R A C T
Demonstration of bronchial hyperresponsiveness is a key feature in asthma diagnosis. Methacholine challenge has proved to be a highly sensitive test to diagnose asthma in patients with chronic respiratory symptoms and preserved baseline lung function (FEV1 $>70 \%$ pred.) but is time consuming and may sometimes reveal unpleasant to the patient.

We conducted a retrospective study on 270 patients recruited from the University Asthma Clinic of Liege. We have compared the values of several lung function indices and fractional exhaled nitric oxide (FeNO) in predicting a provocative methacholine concentration $\leq 16 \mathrm{mg} / \mathrm{ml}$ on a discovery cohort of 129 patients (57 already on ICS) and on a validation cohort of 141 patients (66 already on ICS).

In the discovery study $(n=129), 85$ patients $(66 \%)$ had a positive methacholine challenge with PC20M $\leq 16 \mathrm{mg} / \mathrm{ml}$. Those patients had lower baseline \% predicted FEV1 (92\% vs. 100\%; p < 0.01), lower FEV1/FVC ratio (79\% vs. 82\%; $\mathrm{p}<0.05)$, higher RV/TLC ratio (114\% vs. 100\%; p < 0,0001), lower SGaw (specific conductance) (0.76 vs. 0.95; p < 0,001) and higher FeNO (29 ppb vs. 19 ppb; p < 0,01). When performing ROC curve the RV/TLC ratio provided the greatest AUC (0.74, p < 0.001), sGAW had intermediate AUC of 0.69 ( $\mathrm{p}<0.001$ ) while FeNO, FEV1 and FEV1/FVC ratio were modestly predictive (AUC of 0.65 ( $\mathrm{p}<0.05$ ), 0,67 ( $\mathrm{p}<0.001$ ) and 0,63 ( $<<0.001$ ). These results were confirmed in the validation study ( $\mathrm{n}=141$ ). Based on a logistic regression analysis, significant variables associated with positive methacholine challenge were FeNO and RV/TLC (\% Pred). A combined application of FeNO and RV/TLC (\% Pred) for predicting the PC20M had a specificity of $85 \%$, a sensitivity of $59 \%$ and an AUC of 0.79 . In the validation study, three variables (RV/TLC, FeNO and FEV1) were independently associated with positive methacholine challenge and the combination of these three variables yielded a specificity of $77 \%$, a sensitivity of $39 \%$ and an AUC of 0.77 .
\end{abstract}

The RV/TLC ratio combined to FeNO may be of interest to predict significant methacholine bronchial hyperresponsiveness.

\section{Introduction:}

Excessive airway fluctuation is a fundamental feature in patient with asthma. It could be demonstrated by a significant reversibility of FEV1 ( $>12 \%$ reversibility and $200 \mathrm{~mL}$ ) following $400 \mu \mathrm{g}$ inhaled salbutamol when FEV1 $<80 \%$ predicted or by bronchial hyperresponsiveness to methacholine challenge when FEV1 > 70\% predicted [1]. Methacholine challenge test (MCT) has proved to be a highly sensitive test to diagnose asthma in patients with chronic respiratory symptoms and preserved baseline lung function [2,3]. However, the MCT is time consuming and unpleasant for the patient. Recent surveys indicate that wrong asthma diagnosis may be present up to $30 \%$ of patients who received an asthma diagnosis in the community [4]. Therefore, finding a test or a combination of tests that may predict a positive MCT could be helpful for the clinician to diagnose asthma. On the other hand the severity of bronchial hyperresponsiveness to methacholine was shown to correlate with poor asthma control [5] and reducing the severity of methacholine responsiveness with stepping up ICS improved asthma control [6].

Here we have compared the values of several lung function indices obtained during routine lung function assessment using body plethysmography together with measurement fractional exhaled nitric oxide (FeNO) in predicting a provocative methacholine concentration $\leq 16 \mathrm{mg} / \mathrm{ml}$. We also investigated the relationship between the severity of methacholine bronchial hyperresponsiveness and baseline lung function indices and FeNO among those who tested positive

\footnotetext{
* Corresponding author.

E-mail address: nicolas.bougard@chuliege.be (N. Bougard).
} 
Table 1

demographic and functional patient characteristics.

\begin{tabular}{|c|c|c|}
\hline & Cohort 1 & Cohort 2 \\
\hline Number & 129 & 141 \\
\hline \multirow[t]{2}{*}{$\mathrm{PC} 20 \mathrm{M} \leq 16 \mathrm{mg} / \mathrm{ml}(\mathrm{Y} / \mathrm{N})$} & 85 Y $(66 \%)$ & 96 Y $(68 \%)$ \\
\hline & $44 \mathrm{~N}(34 \%)$ & $45 \mathrm{~N}(32 \%)$ \\
\hline \multirow[t]{2}{*}{ Atopie $(\mathrm{Y} / \mathrm{N})$} & 58 Y (45\%) & 71 Y (50\%) \\
\hline & $71 \mathrm{~N}(55 \%)$ & $70 \mathrm{~N}(50 \%)$ \\
\hline \multirow[t]{2}{*}{$\operatorname{Sex}(\mathrm{F} / \mathrm{M})$} & $78 \mathrm{~F}(60 \%)$ & $82 \mathrm{~F}(58 \%)$ \\
\hline & $51 \mathrm{M}(40 \%)$ & $59 \mathrm{M}(42 \%)$ \\
\hline Age & $50 \pm 15$ & $51 \pm 15$ \\
\hline \multirow[t]{2}{*}{ Current smoking $(\mathrm{Y} / \mathrm{N})$} & $14 \mathrm{Y}(11 \%)$ & $17 \mathrm{Y}(12 \%)$ \\
\hline & $115 \mathrm{~N}(89 \%)$ & $124 \mathrm{~N}(88 \%)$ \\
\hline \multirow[t]{2}{*}{ ICS $(\mathrm{Y} / \mathrm{N})$} & 57 Y (44\%) & 66 Y (47\%) \\
\hline & $72 \mathrm{~N}(56 \%)$ & $75 \mathrm{~N}(53 \%)$ \\
\hline FeNO (ppb) & $22(14-47)$ & $23(14-39)$ \\
\hline sGAW (1/kPa*s) & $0.82(0.63-1.01)$ & $0.76(0.58-0.98)$ \\
\hline RV/TLC (\% pred) & $109 \pm 17$ & $106 \pm 23$ \\
\hline FEV1 (\% pred) & $95 \pm 14$ & $91 \pm 16$ \\
\hline FEV1/FVC (\%) & $80 \pm 7$ & $78 \pm 8$ \\
\hline Blood Neutrophils $(1 / \mu \mathrm{l})$ & $3750(2812-4662)$ & 3767 (2999-4801) \\
\hline Blood Eosinophils $(1 / \mu \mathrm{l})$ & 201 (109-329) & $151(81-279)$ \\
\hline Sputum Neutrophils (\%) & $63(45-78)$ & $78(43-80)$ \\
\hline Sputum Eosinophils (\%) & $1.8(0.5-6.4)$ & $1.6(0.4-5.2)$ \\
\hline Disease onset (years) & $10(3-25)$ & $8(3-26)$ \\
\hline
\end{tabular}

(PC20M $\leq 16 \mathrm{mg} / \mathrm{ml}$ ). We first analysed the predicting values of FEV1, FEV1/FVC ratio, specific conductance (sGaw), RV/TLC ratio and FeNO on a discovery (or training) cohort of 129 patients (57 already on ICS) and the results were confirmed on a validation cohort of 141 patients (66 already on ICS) recruited from our asthma clinic.

\section{Methods}

We conducted a retrospective review of patients records from our pulmonary function laboratory files. We selected patients from our asthma clinic that had undergone spirometry, volume measurement by body plethysmography, FeNO measurement and a methacholine challenge test from January 2017 to December 2017. We also selected a second cohort of patients from January 2018 to December 2018 as a validation cohort. These investigations were utilized to assess patients with recurrent respiratory symptoms of cough, breathlessness and/or wheezing and baseline FEV1 above 70\% predicted. Almost half of these patients were already receiving inhaled corticosteroids. Demographic and functional patient characteristics are indicated in Table 1. The demographic and functional characteristic of the validation cohort were similar to those of the derivation cohort.

\subsection{Exhaled nitric oxide}

Exhaled nitric oxide was measured by a chemoluminescence analyser (NIOX, aerocrine, Stockholm, Sweden) at a flow rate of $50 \mathrm{~mL} / \mathrm{s}$. This measure was conforming to the ATS/ERS task force's recommendations [7].

\subsection{Pulmonary function testing}

All Pulmonary function tests were performed according to the ERS/ ATS criteria [8]. Spirometry was performed using an electronic spirometer connected in real time to a computer (spirobank, MIR, Rome, Italy). All manoeuvres were repeated three times and the best FEV1 value was kept by the software program (winspiro, MIR). Methacholine chloride was purchased as powder (Provocholine $1280 \mathrm{mg}$; Metapharm, Brantford, Ontario, Canada) and dissolved in $\mathrm{NaCl} 0.9 \%$ by the hospital pharmacy to give appropriate concentrations. The methacholine challenge was performed by using a Hudson jet nebulizer (Hudson RCI; Micro Mist, Research Triangle Park, NC) activated by an airflow rate of $6 \mathrm{~L} /$ minute and delivering $0.3 \mathrm{~mL} /$ minute. MCT was performed according to a slightly modified Cockroft's method. Patients successively inhaled by tidal breathing for 2 min fourfold increasing concentrations of methacholine chloride from 0.06 to $16 \mathrm{mg} / \mathrm{ml}$ as described previously [9]. The aerosol was generated by a jet nebulizer (Hudson, Temecula, CA, USA), whose characteristics were described previously [10]. Spirometry data and RV/TLC were expressed as percent predicted of normal reference value $[11,12]$. The specific conductance was determined by implementing a least-squeared fit of the line through the specific conductance loop at a defined fixed flow of 0.5 L/s $[13,14]$.

\subsection{Statistical analysis}

The results were expressed as mean \pm SD for continuous and normally distributed variables while we preferred median and interquartile ranges (IQR) for skewed distributions. For categorical variables, the number of observations and percentages were given in each category. Comparison between the two groups was made with unpaired $t$ test or Mann-Witney test respectively when the normality test using the method of Kolmogorov and Smirnov was passed or not. Correlations were made using the Spearman coefficient of correlation.

Receiver-operating characteristic (ROC) curves were constructed to define the accuracy of sGAW, RV/TLC, FEV1, FEV1/FVC and FENO to predict a positive MCT. This method determines the accuracy of the binary classification models and the area under the curve (AUC) is a common measure of its exact evaluation. Cut-off was defined as the value giving the best sum of sensitivity and specificity.

Logistic regression analysis was performed to assess the relationship between the binary outcomes (PC20M) and five covariates, sGAW, RV/ TLC, FEV1, FEV1/FVC, FeNO. Ordinary estimation of unknown parameters in the model was calculated by GLM (generalized linear mixed model) function by maximum likelihood. The ability of the equation to predict a positive MCT was verified in an independent cohort of 141 patients recruited from 1 January 2018 to 31 December 2018. The results were considered to be significant at the $5 \%$ critical level ( $<<0.05$ ). All analyses were performed using the R software.

\section{Results}

\subsection{Ability of lung function indices and FeNO to predict positive methacholine challenge in the discovery cohort}

In the discovery cohort, $85 / 129$ patients $(66 \%)$ had a positive methacholine challenge with PC20M $\leq 16 \mathrm{mg} / \mathrm{ml}$ (Table 1). Those patients had lower baseline percent predicted FEV1 $(\mathrm{p}<0.01$ ), lower FEV1/FVC ratio ( $\mathrm{p}<0.05$ ), higher RV/TLC ratio ( $\mathrm{p}<0.0001$ ), lower sGaw (specific conductance) $(\mathrm{p}<0.001)$ and higher FeNO ( $\mathrm{p}<0.01)$.

When performing ROC curve the RV/TLC ratio provided the greatest AUC (0.74, p < 0.001) (Fig. 1) while AUC from sGaw, FEV1, FEV1/FVC ratio and FeNO were modestly predictive ranging between 0.69 and 0.63 (Table 2). At a threshold of 99\% predicted RV/TLC had a sensitivity and specificity of $54 \%$ and $87 \%$ respectively (Table 2 ).

We then performed a logistic regression with the binary outcomes (PC20M) and the 5 covariates (sGAW, RV/TLC, FeV1, FEV1/FVC and FeNO). The logistic regression model assumes that

$$
\begin{aligned}
& \log \left(\frac{P(P C 20 M)}{1-P(P C 20 M)}\right) \\
& \quad=\beta_{0}+\beta_{1} F e N O+\beta_{2} S G A W+\beta_{3} R V / T L C+\beta_{4} F E V 1+\beta_{5} F E V 1 / F V C
\end{aligned}
$$

Ordinary estimation of unknown parameters in the model was calculated by GLM (generalized linear mixed model) function by maximum likelihood. Estimation results are presented in Table 3.1. It turned out that only two variables, RV/TLC and FeNO, had a significant independent association with a positive MCT. Estimation results for the 


\section{RVITLC (\% Pred)}

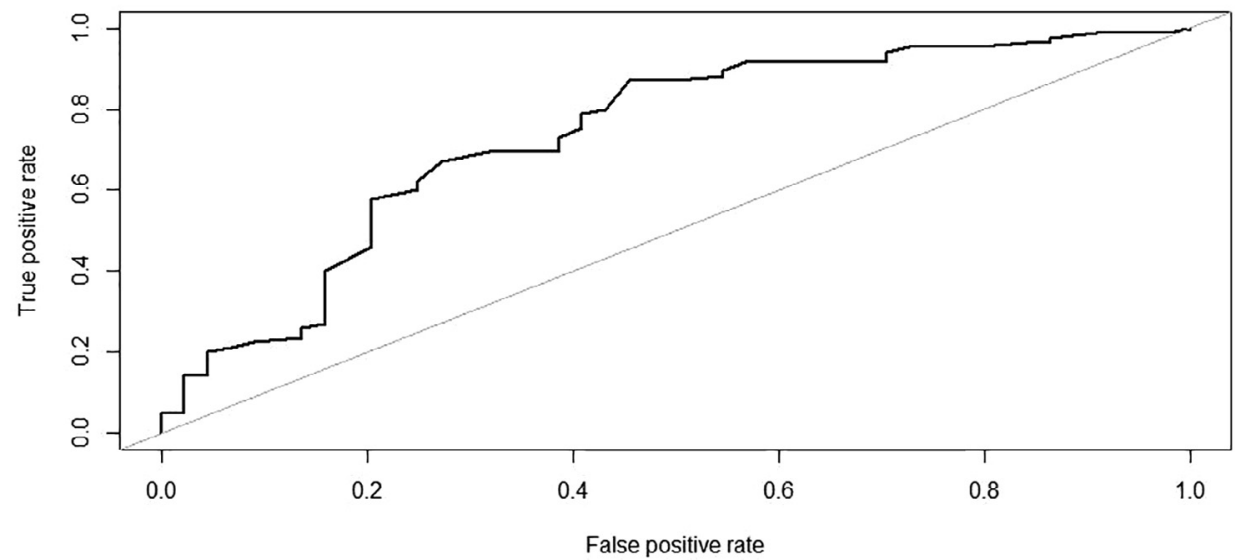

Fig. 1. Receiver-operating characteristic curve (ROC) for the discovery cohort to determine the RV/TLC value which best identified a positive methacholine challenge test (MCT) with PC20M $\leq 16 \mathrm{mg} / \mathrm{ml}$. The optimum cut-off point was $99 \%$ pred. (AUC 0.735 , sensitivity $54.5 \%$, specificity $87 \%$, VPP $78.7 \%$, VPN $68.6 \%$, $\mathrm{P}<0.001)$.

significant variables are presented in Table 3.2. We then fit the model again only taking into account the two significant variables. Compared to the one with the five variables, the two variables model had a smaller AIC (139.67 VS 141.62) which indicates a better-fitting model. Therefore the best model assumes that

$\log \left(\frac{P(P C 20 M)}{1-P(P C 20 M)}\right)=\beta_{0}+\beta_{1} R V / T L C+\beta_{2} F e N O$

The AUC, threshold, sensitivity, and specificity are reported in Table 3.3. The Table 3.4 showed the Confusion Matrix. The ROC curve is represented in Fig. 2.

A combined application of FeNO and RV/TLC (\% Pred) for predicting the PC20M resulted in an area under curves equals to 0.79 with the cut-off point of 0.464 and a sensitivity and specificity reaching $59 \%$ and $85 \%$ respectively.

\subsection{Ability of lung function indices and FeNO to predict positive} methacholine challenge in the validation cohort

The baseline demographic and lung function characteristics of the patients of the validation cohort (cohort 2) were very similar to the cohort 1 and shown in Table 1.

In the validation cohort it is again RV/TLC ratio that provided the greatest AUC (0.75) to predict positive PC20M (Fig. 3). At a threshold of $102 \%$ predicted, RV/TLC had a sensitivity and a specificity of $71 \%$ and $68 \%$ respectively (Table 4 ). Other lung function indices performed less well with lower AUC and the FeNO AUC was even not significant (Table 4). After multiple logistic regression, three variables (RV/TLC, FeNO and FEV1) had a significant predicting effect on the results of PC20M. Estimation results are presented in Tables 5.1 and 5.2 respectively with and without non-significant variables. We performed a logistic regression with the binary outcomes (PC20M) and these 3 covariates. The logistic regression model assumes that
Table 3.1

Parameter estimation for logistic regression on the discovery cohort for the five indices model.

\begin{tabular}{|c|c|c|c|c|c|}
\hline & \multirow[t]{2}{*}{ Odds ratio } & \multicolumn{2}{|c|}{ Confidence Interval } & \multirow[t]{2}{*}{ P-value } & \multirow[t]{2}{*}{ Result } \\
\hline & & Lower & Upper & & \\
\hline Intercept & 8.707 & 0.021 & 3621.31 & 0.555 & Not Significant \\
\hline FeNO & 0.973 & 0.956 & 0.990 & 0.009 & $\begin{array}{l}\text { Significant } \\
(\mathrm{P}<0.05)\end{array}$ \\
\hline sGAW & 3.238 & 0.959 & 10.938 & 0.112 & Not Significant \\
\hline RV/TLC & 0.955 & 0.931 & 0.981 & 0.004 & $\begin{array}{l}\text { Significant } \\
(\mathrm{P}<0.001)\end{array}$ \\
\hline FEV1 & 1.017 & 0.988 & 1.046 & 0.342 & Not Significant \\
\hline FEV1/FVC & 1.003 & 0.945 & 1.064 & 0.929 & Not Significant \\
\hline
\end{tabular}

AIC: 141.62.

$\log \left(\frac{P(P C 20 M)}{1-P(P C 20 M)}\right)=\beta_{0}+\beta_{1} R V / T L C+\beta_{2} F e N O+\beta_{3} F E V 1$

A combined application of FeNO, RV/TLC (\% Pred) and FEV1 (\% Pred) for predicting the PC20M resulted in an AUC of 0.77 and a cut-off point of 0.363 yielding a sensitivity and a specificity of $69 \%$ and $77 \%$ respectively. The AUC, threshold, sensitivity, and specificity are reported in Table 5.3. The table 5.4 showed the Confusion Matrix. The ROC curve is represented in Fig. 4.

When the combined variables were compared each of individual variables, the combination of variables was superior to the FeNO alone in terms of specificity, was superior to the RV/TLC (\% Pred) alone in terms of sensitivity. Combination of variables provided a greater AUC compared to the variables taken alone.

\subsection{Correlation between PC2OM and lung function indices and FeNO}

Among the patients who tested positive to methacholine

Table 2

Values derived from the ROC curves of lung function indices and FeNO for a positive methacholine challenge in the discovery cohort (Cohort 1).

\begin{tabular}{|c|c|c|c|c|c|c|c|}
\hline & AUC & Threshold & Sensitivity & Specificity & VPP & VPN & P-value \\
\hline RV/TLC (\% pred) & 0.735 & 99 & 0.545 & 0.870 & $78.7 \%$ & $68.6 \%$ & $<0.001$ \\
\hline sGAW $\left(1 / \mathrm{kPa}^{*} \mathrm{~s}\right)$ & 0.689 & 0.73 & 0.864 & 0.494 & $87.5 \%$ & $46.9 \%$ & $<0.001$ \\
\hline FeNO (ppb) & 0.645 & 25 & 0.773 & 0.576 & $83.1 \%$ & $48.6 \%$ & $<0.05$ \\
\hline FEV1 (\% pred) & 0.667 & 98 & 0.614 & 0.718 & $78.2 \%$ & $52.9 \%$ & $<0.001$ \\
\hline FEV1/FVC (\%) & 0.626 & 77 & 0.818 & 0.459 & $83 \%$ & $43.9 \%$ & $<0.001$ \\
\hline
\end{tabular}


Table 3.2

Parameter estimation for logistic regression on the discovery cohort for the two indices model.

\begin{tabular}{|c|c|c|c|c|c|}
\hline & \multirow[t]{2}{*}{ Odds ratio } & \multicolumn{2}{|c|}{ Confidence Interval } & \multirow[t]{2}{*}{ P-value } & \multirow[t]{2}{*}{ Result } \\
\hline & & Lower & Upper & & \\
\hline Intercept & 6.433 & 42.489 & 9109.72 & $<0.001$ & Significant $(\mathrm{P}<0.001)$ \\
\hline RV/TLC & -0.058 & 0.921 & 0.967 & $<0.001$ & Significant $(P<0.001)$ \\
\hline FeNO & -0.029 & 0.954 & 0.987 & 0.004 & Significant $(\mathrm{P}<0.05)$ \\
\hline
\end{tabular}

AIC: 139.67.

Table 3.3

Outputs of ROC curve for two full and final models (Cohort 1).

\begin{tabular}{|c|c|c|c|c|c|c|c|c|}
\hline & AUC & Threshold & Sensitivity & Specificity & VPP & VPN & P-value & Accuracy \\
\hline All five Variables & 0.805 & 0.379 & 0.75 & 0.753 & $85.3 \%$ & $61.1 \%$ & $<0.001$ & 0.75 \\
\hline FeNO RV/TLC & 0.787 & 0.464 & 0.591 & 0.847 & $80 \%$ & $66.7 \%$ & $<0.001$ & 0.76 \\
\hline
\end{tabular}

Table 3.4

Confusion Matrix (Prediction-accuracy output) (Cohort 1).

\begin{tabular}{llll}
\hline & & Real value \\
\cline { 3 - 4 } & & 0 & 1 \\
\hline Predicted & 0 & 72 & 18 \\
Value & 1 & 13 & 24 \\
\hline
\end{tabular}

Accuracy: 0.759

(PC20M $\leq 16 \mathrm{mg} / \mathrm{ml}$ ) in the training cohort (cohort 1 ), the magnitude of PC20M was significantly and inversely correlated with FeNO ( $\mathrm{r}=$ $0.37 ; \mathrm{p}<0.001$ ) (Fig. 5a) but was poorly correlated with the other indices: FEV1 $(r=0.06 ; p>0.5)$, FEV1/FVC $(r=0.20 ; p=0.06)$, sGaw ( $\mathrm{r}=0.11 ; \mathrm{p}>0.1)$, RV/TLC $(\mathrm{r}=-0,18 ; \mathrm{p}>0.05)$. In the validation cohort (cohort 2) the magnitude of PC20M was again inversely related to FeNO $(\mathrm{r}=-0.22, \mathrm{p}<0.05)$ (Fig. 5b), positively related to sGaw ( $\mathrm{r}=0.25, \mathrm{p}<0.05)$ but not significantly related to FEV1 $(r=0.15)$, FEV1/FVC $(r=0.11)$ and RV/TLC $(r=-0.08)$ (p > 0.05 for all).

\section{Discussion}

Our study shows that a combination of RV/TLC measured by plethysmography and FeNO provides the best strategy to predict the positivity of a methacholine challenge in patients with symptoms suggestive of asthma. It indicates that both gas trapping and epithelial cell activation may play key roles in determining the presence of bronchial hyperresponsiveness.

Our data regarding the ratio RV/TLC are in keeping with what Stanbrook et al reported more than 25 years ago [15]. They found that $\mathrm{RV} / \mathrm{TLC}$ was a specific (81\%) but insensitive (29\%) index of positive methacholine challenge test with a threshold set at $120 \%$ predicted. In our study sensitivity was clearly higher and above $50 \%$ with specificity above $60 \%$ in both cohorts. This is explained by the differences between cut-points. Ours were defined by ROC curves and turned around 100\% in both cohorts. Therefore, our cut-points are much lower than the arbitrarily $120 \%$ reported in the study of Stanbrook et al. As Stanbrook et al did not give much details about their patients, likely some of these patients had COPD. Our cohorts were made of patients with both suspected asthma and confirmed asthma in whom methacholine challenge was performed to assess the extent of bronchial hyperresponsiveness as a component of the disease. Overall Stanbrook'study and ours point to the interest of looking at the index RV/TLC in asthmatics or in patients with suspicion of asthma. Yet, this parameter is seldom evoked in asthma literature while it has long been recognised as an important sign of lung hyperdistension in COPD. Moreover, our current study also aligns with the recent ATLANTIS study from Postma et al showing renewed interest for small airway dysfunction indices, and for RV/TLC in particular, which appeared to correlate with asthma control [16].

In our study, traditional lung function indices reflecting more proximal airway obstruction like the ratio FEV1/FVC or sGaw performed less well than RV/TLC and, interestingly, did not emerge convincingly in the multiple logistic regression model. Our results would suggest that baseline distal airway obstruction, reflected by increased $\mathrm{RV} / \mathrm{TLC}$, may be critical in predicting positive methacholine challenge.

\section{Logidtic Prediction}

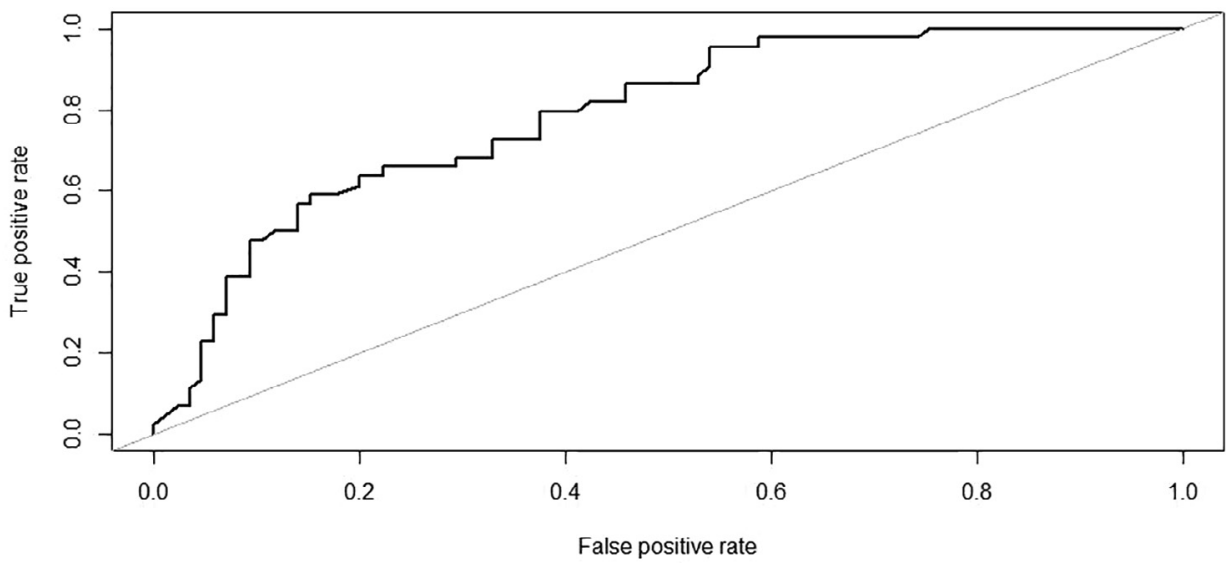

Fig. 2. Receiver-operating characteristic curve (ROC) for the discovery cohort to determine the combination of RV/TLC and FeNO value which best identified a positive methacholine challenge test (MCT) with PC20M $\leq 16 \mathrm{mg} / \mathrm{ml}$. The optimum cut-off point was 0.464 (AUC 0.787 , sensitivity $59.1 \%$, specificity $84.7 \%, \mathrm{P}<0.001$ ). 


\section{RVITLC (\% Pred)}

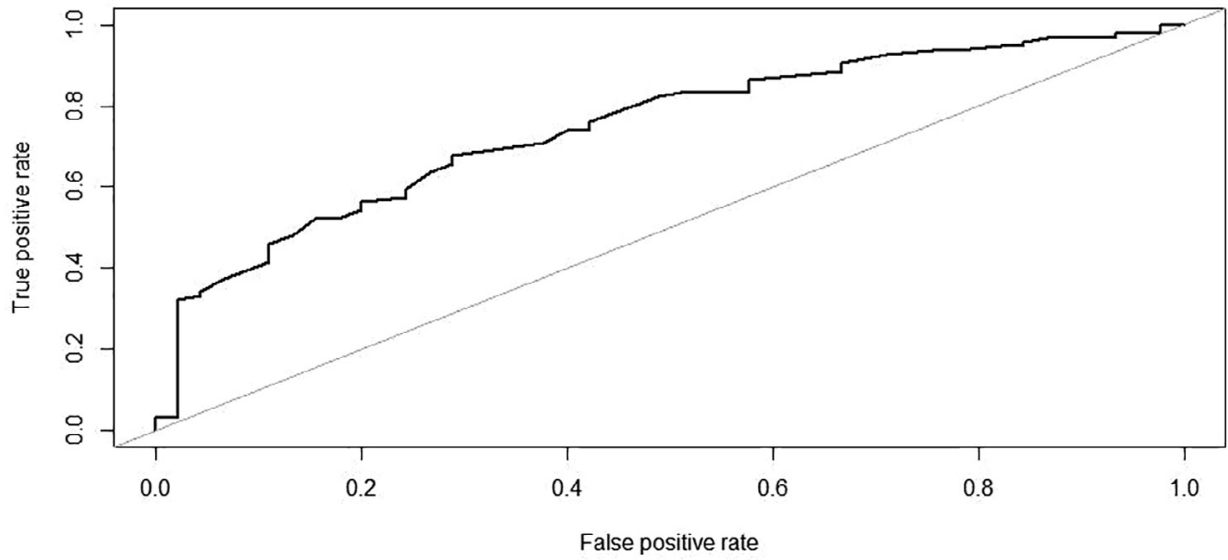

Fig. 3. Receiver-operating characteristic curve (ROC) for the validation cohort to determine the RV/TLC value which best identified a positive methacholine challenge test (MCT) with PC20M $\leq 16 \mathrm{mg} / \mathrm{ml}$. The optimum cut-off point was $102 \%$ pred. (AUC 0.748 , sensitivity $71.1 \%$, specificity $67.7 \%$, VPP $83.3 \%$, VPN $50.8 \%$, $\mathrm{P}<0.001)$.

Table 4

Values derived from the ROC curves of lung function indices and FeNO for a positive methacholine challenge in the validation cohort (cohort 2).

\begin{tabular}{|c|c|c|c|c|c|c|c|}
\hline & AUC & Threshold & Sensitivity & Specificity & VPP & VPN & $\mathrm{P}$-value \\
\hline RV/TLC (\% pred) & 0.748 & 102 & 0.711 & 0.677 & $83.3 \%$ & $50.8 \%$ & $<0.001$ \\
\hline sGAW (1/kPa*s) & 0.620 & 0.87 & 0.511 & 0.708 & $75.6 \%$ & $45.1 \%$ & $<0.05$ \\
\hline FeNO (ppb) & 0.559 & 32 & 0.867 & 0.385 & $86 \%$ & $39.8 \%$ & 0.13 \\
\hline FEV1 (\% pred) & 0.689 & 99 & 0.511 & 0.833 & $78.4 \%$ & $59 \%$ & $<0.001$ \\
\hline FEV1/FVC (\%) & 0.683 & 79 & 0.689 & 0.667 & $82.1 \%$ & $49.2 \%$ & $<0.001$ \\
\hline
\end{tabular}

Table 5.1

Parameter estimation for logistic regression on the validation cohort for the five indices model.

\begin{tabular}{|c|c|c|c|c|c|}
\hline & \multirow[t]{2}{*}{ Odds ratio } & \multicolumn{2}{|c|}{ Confidence Interval } & \multirow[t]{2}{*}{ P-value } & \multirow[t]{2}{*}{ Result } \\
\hline & & Lower & Upper & & \\
\hline Intercept & 0.215 & 0.0007 & 69.63 & 0.661 & Not Significant \\
\hline FeNO & 0.983 & 0.967 & 0.999 & 0.083 & $\begin{array}{l}\text { Significant } \\
(\mathrm{P}<0.1)\end{array}$ \\
\hline sGAW & 0.792 & 0.244 & 2.571 & 0.744 & Not Significant \\
\hline RV/TLC & 0.971 & 0.950 & 0.992 & 0.025 & $\begin{array}{l}\text { Significant } \\
(\mathrm{P}<0.05)\end{array}$ \\
\hline FEV1 & 1.03 & 1.001 & 1.061 & 0.087 & $\begin{array}{l}\text { Significant } \\
(\mathrm{P}<0.1)\end{array}$ \\
\hline FEV1/FVC & 1.021 & 0.962 & 1.084 & 0.561 & Not Significant \\
\hline
\end{tabular}

AIC: 161.15

Table 5.2

Parameter estimation for logistic regression on the validation cohort for the three indices model.

\begin{tabular}{llllll}
\hline & Odds ratio & \multicolumn{2}{l}{ Confidence Interval } & \multirow{2}{*}{ P-value } & Result \\
\cline { 3 - 4 } & & Lower & Upper & & \\
\hline Intercept & 0.774 & 0.018 & 33.229 & 0.911 & Not Significant \\
RV/TLC & 0.970 & 0.951 & 0.989 & 0.012 & Significant $(\mathrm{P}<0.05)$ \\
FeNO & 0.983 & 0.967 & 0.998 & 0.074 & Significant $(\mathrm{P}<0.1)$ \\
FEV1 & 1.034 & 1.006 & 1.061 & 0.042 & Significant $(\mathrm{P}<0.05)$ \\
\hline
\end{tabular}

AIC: 157.5.

We can speculate that methacholine deposition in the airways may be more proximal if the RV/TLC is higher, thereby increasing the fall in FEV1 upon methacholine inhalation, which is an index better reflecting changes in calibre of intermediate to large airways during the challenge. However, if RV/TLC appears to be good at predicting positive methacholine challenge, it failed to correlate with the magnitude of bronchial hyperresponsiveness in the patients who had a PC20M below
$16 \mathrm{mg} / \mathrm{ml}$, which is in keeping with what was reported by Stanbrook et al.

The link between asthma and FeNO has been extensively studied over the last 20 years. We have previously reported that FeNO had a poor sensitivity but a good specificity and positive predictive value for a PC20 $<16 \mathrm{mg} / \mathrm{ml}$ in patients referred by chest physicians to a lung function laboratory for symptoms suggestive of asthma and normal spirometry [17]. Overall recent meta-analysis has shown that FeNO has low sensitivity but acceptable specificity to make an asthma diagnosis [18]. The interest of our current study is that it shows that, though not impressive in ROC curve, the contribution of FeNO emerged after multivariate logistic regression. This would suggest that the effect of FeNO may be counteracted by other variables to which it is linked. FeNO is seen as a biomarker of epithelial cell activation in a T2 environment and has been related to the magnitude of airway eosinophilic inflammation [19]. However, FeNO has also been shown to be dependent on the airway calibre, with a reduction of its level in exhaled air when bronchial obstruction develops and reduces airway calibre [20]. As lower baseline airway calibre also contributes to bronchial hyperesponsiveness as indicated by the predictive value of baseline FEV1 on the positivity of PC20M, it may explain why FeNO, though not performing strong in the prediction of positive PC20M, emerged as significant contributor after multiple logistic regression. Our results also show that combining RV/TLC and FeNO in a multiple logistic model improves with an AUC reaching 0.79 and an accuracy of $76 \%$.

Interestingly, FeNO was the index that correlated the most convincingly with the severity of bronchial hyperresponsiveness among the subjects who tested positive to methacholine challenge. This confirms, in a mixed population including ICS treated patients, studies that investigated corticoid naïve patients $[21,3]$. This observation supports the link between epithelial cell activation and smooth muscle airway reactivity.

Finally we acknowledge that our two cohorts of patients were a mix of T2 and non T2 mild to moderate asthma with a large range in FeNO values as well as in sputum and blood eosinophil counts. The existence the two types of asthma is a well accepted observation today, both in mild to moderate and in a severe asthma [22-24]. The average values 
Table 5.3

Outputs of ROC curve for two full and final models (Cohort 2).

\begin{tabular}{|c|c|c|c|c|c|c|c|c|}
\hline & AUC & Threshold & Sensitivity & Specificity & VPP & VPN & P-value & Accuracy \\
\hline All five Variables & 0.771 & 0.364 & 0.689 & 0.781 & $84.3 \%$ & $59.6 \%$ & $<0.001$ & 0.752 \\
\hline $\begin{array}{l}\text { FeNO } \\
\qquad \begin{array}{l}\text { RV/TLC } \\
\text { FEV1 }\end{array}\end{array}$ & 0.769 & 0.363 & 0.689 & 0.771 & $84 \%$ & $58.5 \%$ & $<0.001$ & 0.745 \\
\hline
\end{tabular}

Table 5.4

Confusion Matrix (Prediction-accuracy output) (Cohort 2).

\begin{tabular}{llll}
\hline & \multicolumn{2}{l}{ Real value } \\
\cline { 2 - 3 } & & 0 & 1 \\
\hline Predicted & 0 & 74 & 14 \\
Value & 1 & 22 & 31 \\
\hline
\end{tabular}

Accuracy: 0.745 .

of inflammatory biomarkers in the two cohorts presented in this study are rather similar to the ones we previously reported from patients recruited from the same ambulatory care facilities [25]. Thus, we believe our finding applies to a general asthmatic population recruited in a secondary care centre.

We conclude that taking into account both an index of lung distension and airway epithelial cell activation may help the clinician to predict the presence of bronchial hyperresponsiveness to methacholine in patients. Combining a lung function index with an airway inflammatory biomarker is a suitable strategy to approach the existence of bronchial hyperresponsiveness.

\section{CRediT authorship contribution statement}

N. Bougard: Writing - original draft, Visualization, Writing - review \& editing. H. Nekoee: Methodology, Formal analysis, Validation. F. Schleich: Investigation. F. Guissard: Resources, Data curation. V. Paulus: Resources, Data curation. AF Donneau: Software, Supervision. R. Louis: Conceptualization, Validation, Project administration, Supervision.

\section{Acknowledgment}

We acknowledge the financial support of a federal government grant EOS (excellence of science), Belgium (30565447).
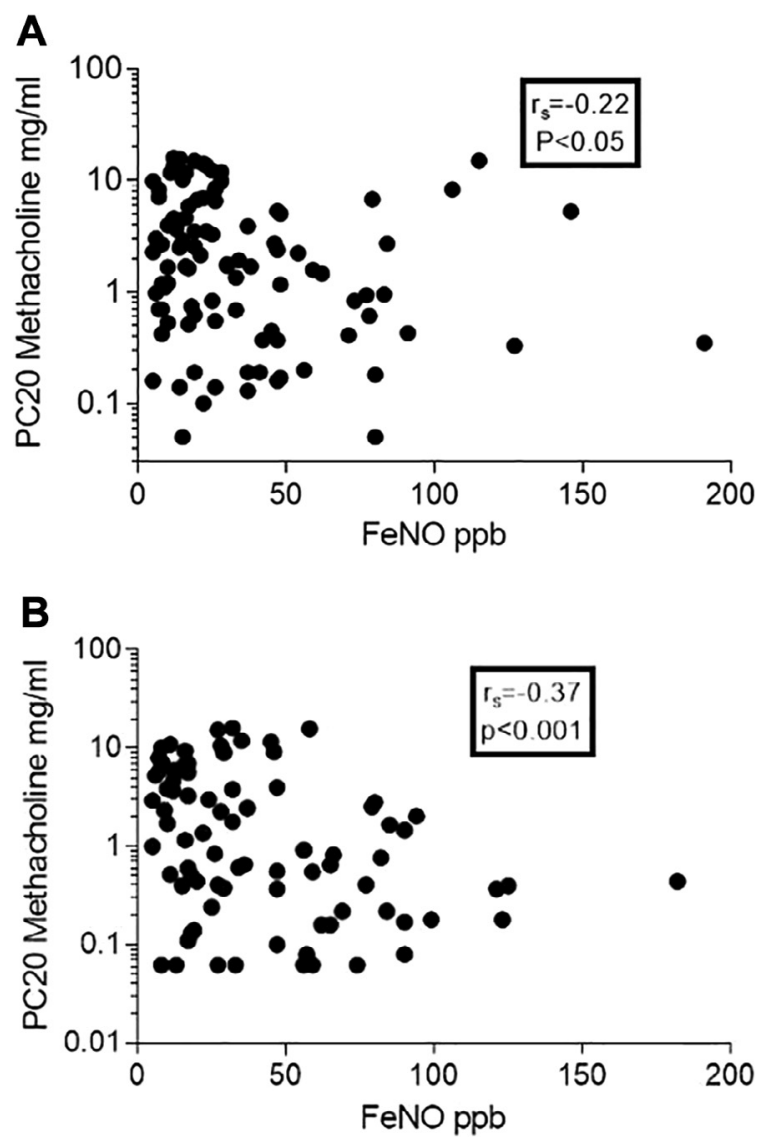

Fig. 5. Correlation between FeNO and PC20 methacholine in the cohort 1 (upper panel) and the cohort 2 (lower panel). $R_{s}$ is the spearman coefficient of correlation.

\section{Logidtic Prediction}

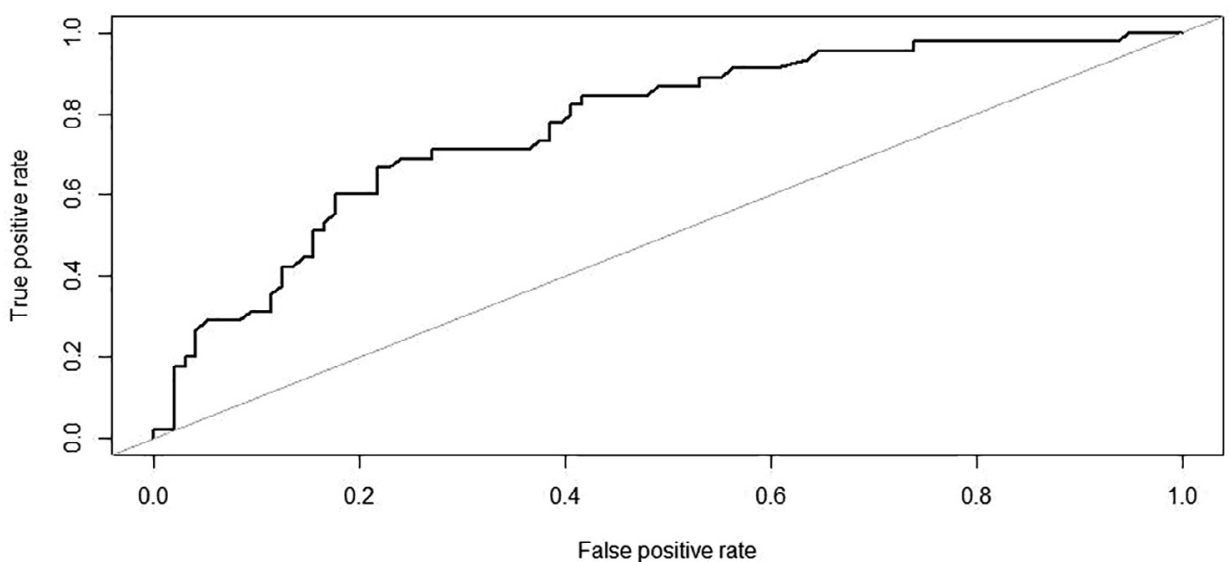

Fig. 4. Receiver-operating characteristic curve (ROC) for the validation cohort to determine the combination of RV/TLC, FeNO and FEV1 value which best identified a positive methacholine challenge test (MCT) with PC20M $\leq 16 \mathrm{mg} / \mathrm{ml}$. The optimum cut-off point was 0.363 (AUC 0.769 , sensitivity $68.9 \%$, specificity $77.1 \%$, $\mathrm{P}<0.001)$ 


\section{References}

[1] 2019 GINA Main Report [Internet]. Global Initiative for Asthma - GINA. [cited 2020 Jan 29]. Available from: https://ginasthma.org/gina-reports/.

[2] P. Nair, J.G. Martin, D.C. Cockcroft, M. Dolovich, C. Lemiere, L.-P. Boulet, et al., Airway hyperresponsiveness in asthma: measurement and clinical relevance, J. Allergy Clin. Immunol. Practice 5 (3) (2017) 649-659.e2.

[3] R. Louis, N. Bougard, F. Guissard, V. Paulus, M. Henket, F. Schleich, Bronchodilation test with inhaled salbutamol versus bronchial methacholine challenge to make an asthma diagnosis: do they provide the same information? J. Allergy Clin. Immunol. Pract. (2019) 18.

[4] S.D. Aaron, L.P. Boulet, H.K. Reddel, A.S. Gershon, Underdiagnosis and overdiagnosis of asthma, Am. J. Respir. Crit. Care Med. 198 (8) (2018) 1012-1020.

[5] V. Quaedvlieg, J. Sele, M. Henket, R. Louis, Association between asthma control and bronchial hyperresponsiveness and airways inflammation: a cross-sectional study in daily practice, Clin. Exp. Allergy 39 (12) (2009) 1822-1829.

[6] J.K. Sont, L.N. Willems, E.H. Bel, J.H. van Krieken, J.P. Vandenbroucke, P.J. Sterk, Clinical control and histopathologic outcome of asthma when using airway hyperresponsiveness as an additional guide to long-term treatment. The AMPUL Study Group, Am. J. Respir. Crit. Care Med. 159 (4 Pt 1) (1999) 1043-1051.

[7] American Thoracic Society, European Respiratory Society, ATS/ERS recommendations for standardized procedures for the online and offline measurement of exhaled lower respiratory nitric oxide and nasal nitric oxide, Am. J. Respir. Crit. Care Med 171 (8) (2005) 912-930.

[8] M.R. Miller, J. Hankinson, V. Brusasco, F. Burgos, R. Casaburi, A. Coates, et al., Standardisation of spirometry, Eur. Respir. J. 26 (2) (2005) 319-338.

[9] R. Louis, J. Sele, M. Henket, D. Cataldo, J. Bettiol, L. Seiden, et al., Sputum eosinophil count in a large population of patients with mild to moderate steroid-naive asthma: distribution and relationship with methacholine bronchial hyperresponsiveness, Allergy 57 (10) (2002) 907-912.

[10] R. Louis, T. Bury, J.L. Corhay, M.F. Radermecker, Acute bronchial and hematologic effects following inhalation of a single dose of PAF. Comparison between asthmatics and normal subjects, Chest 106 (4) (1994) 1094-1099.

[11] P.H. Quanjer, G.J. Tammeling, J.E. Cotes, O.F. Pedersen, R. Peslin, J.C. Yernault, Lung volumes and forced ventilatory flows. Work Group on Standardization of Respiratory Function Tests. European Community for Coal and Steel. Official position of the European Respiratory Society, Rev. Mal. Respir. 11 (Suppl 3) (1994) 5-40.

[12] G. Laszlo, Standardisation of lung function testing: helpful guidance from the ATS/ ERS Task Force, Thorax 61 (9) (2006) 744-746.
[13] J. Stocks, S. Godfrey, C. Beardsmore, E. Bar-Yishay, R. Castile, ERS/ATS task force on standards for infant respiratory function testing. European Respiratory Society/ American Thoracic Society. Plethysmographic measurements of lung volume and airway resistance. ERS/ATS Task Force on Standards for Infant Respiratory Function Testing. European Respiratory Society/American Thoracic Society, Eur. Respir. J. 17 (2) (2001) 302-312.

[14] Z. Hantos, G. Galgóczy, B. Daróczy, K. Dombos, Computation of the equivalent airway resistance, RES 36 (2) (1978) 64-72.

[15] M.B. Stanbrook, K.R. Chapman, S. Kesten, Gas trapping as a predictor of positive methacholine challenge in patients with normal spirometry results, Chest 107 (4) (1995) 992-995.

[16] D.S. Postma, C. Brightling, S. Baldi, M. Van den Berge, L.M. Fabbri, A. Gagnatelli, et al., Exploring the relevance and extent of small airways dysfunction in asthma (ATLANTIS): baseline data from a prospective cohort study, Lancet Respir. Med. 7 (5) (2019) 402-416.

[17] F.N. Schleich, R. Asandei, M. Manise, J. Sele, L. Seidel, R. Louis, Is FENO50 useful diagnostic tool in suspected asthma? Int. J. Clin. Pract. 66 (2) (2012) 158-165.

[18] S. Karrasch, K. Linde, G. Rücker, H. Sommer, M. Karsch-Völk, J. Kleijnen, et al., Accuracy of FENO for diagnosing asthma: a systematic review, Thorax 72 (2) (2017) 109-116.

[19] F.N. Schleich, L. Seidel, J. Sele, M. Manise, V. Quaedvlieg, A. Michils, et al., Exhaled nitric oxide thresholds associated with a sputum eosinophil count $\geq 3 \%$ in a cohort of unselected patients with asthma, Thorax 65 (12) (2010) 1039-1044.

[20] A. Haccuria, A. Michils, S. Michiels, A. Van Muylem, Exhaled nitric oxide: a biomarker integrating both lung function and airway inflammation changes, J. Allergy Clin. Immunol. 134 (3) (2014) 554-559.

[21] L.J. Dupont, F. Rochette, M.G. Demedts, G.M. Verleden, Exhaled nitric oxide correlates with airway hyperresponsiveness in steroid-naive patients with mild asthma, Am. J. Respir. Crit. Care Med. 157 (3 Pt 1) (1998) 894-898.

[22] M. Amelink, J.C. de Groot, S.B. de Nijs, R. Lutter, A.H. Zwinderman, P.J. Sterk, et al., Severe adult-onset asthma: a distinct phenotype, J. Allergy Clin. Immunol 132 (2) (2013) 336-341.

[23] F. Schleich, G. Brusselle, R. Louis, O. Vandenplas, A. Michils, C. Pilette, et al., Heterogeneity of phenotypes in severe asthmatics. The Belgian Severe Asthma Registry (BSAR), Respir. Med. 108 (12) (2014) 1723-1732.

[24] J.V. Fahy, Type 2 inflammation in asthma-present in most, absent in many, Nat. Rev. Immunol. 15 (1) (2015) 57-65.

[25] F.N. Schleich, A. Chevremont, V. Paulus, M. Henket, M. Manise, L. Seidel, et al., Importance of concomitant local and systemic eosinophilia in uncontrolled asthma, Eur. Resp. J. 44 (1) (2014) 97-108. 